\title{
Notas para observar la evolución de la historiografía en México en el siglo XX
}

\author{
Guillermo Zermeño PaDilla*
}

\begin{abstract}
RESUMEN
La historiografía mexicana tuvo un proceso de institucionalización desde los años treinta, una vez consolidado el régimen revolucionario. A partir de entonces, hubo una primera etapa que era continuadora del discurso nacional

del siglo XIX revisado a la luz de la revolución. Desde los años sesenta se asiste a una segunda fase que llega a

nuestros dias caracterizada por el enfrentamiento con el legado del régimen revolucionario, lo que significa el final político e historiográfico de una idea de lo nacional construida desde la Independencia.
\end{abstract}

PALABRAS CLAVE Historiografia, México, siglo XX, historia intelectual.

\section{ABSTRACT}

Since the thirtied, after the revolutiionary's Mexico regime has consolidated, the mexicans's historiography has undergone a institucionalization process. The first period of Mexican Historiography continued the national discourse of ninetheen century revised in the light of the revolutionary process. Since the 60 's, this historiography has begun a new phase that reaches until our times, characterized by the confrontation with the revolutionary legacy. This process has meant the political and historical end of a certain idea of the "national" discourse constructed since the independence of Mexico.

\section{KEY WORDS}

Historiography, twentieth century, Mexico, cultural history.

* Universidad Iberoamericana. 
Es una tarea casi imposible querer recapitular el desarrollo de la historiografía mexicana en el siglo xx. A partir de sus primeros atisbos institucionales en la década de los treinta, lo que se mira es una creciente multiplicación de instituciones dedicadas a la formación de nuevos historiadores y a la edición y publicación de toda clase de textos históricos dedicados a dar cuenta de un pasado mexicano muy diverso y disímbolo, posibilitado también por la apertura de nuevos archivos y fuentes documentales.

Siempre en competencia con otras disciplinas preocupadas por descifrar el pasado como la antropología o la sociología, la historiografía ha gozado más o menos de una reputación aceptable, aunque de lo que más se enorgullecerá será de su producción en términos numéricos y tal vez menos de su calidad y de sus contribuciones en el esclarecimiento crítico de las relaciones entre el pasado y el presente. De lo que está cierta es de su inmenso trabajo documental. Acaso debido a estos énfasis el espacio mayor de interpretación y clarificación haya quedado cubierto por mexicanistas extranjeros o saberes afines.

La historiografía "académica" mexicana, en la que también participan otras disciplinas como la medicina, la antropología o la etnografía y la economía, se convierte por tanto en un lugar sumamente difuso y complejo, difícil de precisar por sus múltiples grados de estratificación laboral, que va desde los archivistas, pasa por los hacedores de monografías hasta los intentos de interpretaciones globales, en las que de nuevo intervienen no sólo historiadores (los menos) sino sobre todo, escritores y ensayistas, filósofos y politólogos, nacionales y extranjeros. De modo que los planos discursivos en los que se ha desarrollado la historiografía mexicana la han convertido en un objeto casi inobservable si es que se quiere hacer justicia cabal a todo ese trabajo institucional y esfuerzo de los estudiosos e investigadores. Lo cual hace muy difícil establecer para el siglo xx a los "clásicos» de la historiografía contemporánea, sea esta del período colonial, prehispánico o nacional, fenómeno que sigue siendo más distinguible para etapas historiográficas «prístinas» o anteriores. Fenómeno, claro está, no exclusivo de México, y que obedece al de una economía-política desarrollista y modernizante. Al respecto un factor central que explica la proliferación de textos sobre el pasado será la expansión de los medios de impresión y de la industria editorial que comienza a darse en la década de los veinte.

La escritura "académica" de la historia de México buscará hacerse de un lugar propio entre otras formas - políticas o simplemente motivadas 
por la curiosidad o la nostalgia de los tiempos idos. De por medio no estará ni la propia vivencia o las formas testimoniales de la memoria individual, ni el afán político o sectario de polemizar sobre el pasado, sino las normas asumidas en derredor de la institución académica. Se trata de un proceso de formación institucional que corre al parejo con la consolidación ideológica del régimen de la Revolución mexicana, probablemente no tan diverso al que instaura la novela de la revolución en el centro (con Los de Abajo de Mariano Azuela), o se posesiona de lugares institucionales estratégicos como podrían ser ciertas Facultades de la Universidad Nacional (véase Víctor Díaz Arciniega, «1925: La Revolución cierra filas", en Revista Iberoamericana, N.150, enero-marzo 1990, Madrid). Y en este proceso toman parte sobre todo jóvenes veintiañeros como Daniel Cosío Villegas, quien citado por Díaz Arciniega, escribe en 1925: "En el lenguaje de Ortega y Gasset diriamos que la Revolución no puede triunfar si no cambia la sensibilidad vital, si no surge una nueva generación. Esta generación somos nosotros y por eso afirmamos que nosotros somos la Revolución». Estos jóvenes serán los encargados de construir un futuro "mental» (ideológico) para el régimen de la Revolución, en principio sobre su único sostén de ese momento, "el pasado inmediato, el revolucionario" (Ibíd. pp. 27-8). Con el tiempo, frente al curso de la Revolución institucionalizada, ese "pasado" se irá ensanchando y extendiendo para muchos como Cosío.

Para intentar situar los modos y funciones de la historiografía mexicana en el siglo xx parto, por tanto, de la hipótesis de que estos tienen lugar sobre un trasfondo político central: el proceso de constitución de la hegemonía del régimen en el campo de la ideología, el cual incidirá en la formación y funcionamiento de las instituciones académicas. Estas se presentarán de inicio como los lugares privilegiados para proporcionar saberes seguros y neutros, "no partidistas", sobre el pasado. El Estado delega, por así decirlo, a éstas, sus instancias, el deber de iluminarlo y ennoblecerlo a través del ejercicio y práctica de las humanidades. En esta dirección pretendo hacer observable ese conjunto informe y en apariencia fuera de control que son las textualidades historiográficas.

La pregunta central que articula estas reflexiones es ¿por qué razón la historiografía mexicana descuidó e incluso satanizó el recurso de "la teoría" en la historia, y privilegió "el método" o meras técnicas de 
investigación? Este desacoplamiento del pensamiento y la tecnología tuvo sus repercuciones sin duda en la forma de composición y funcionamiento del gremio. Pero quisiera subrayar a manera de respuesta provisional que la primacia que ha tenido el empirismo sobre una ciencia más reflexiva es un correlato del proceso de construcción de una especie de a priori histórico ("...como conjunto de las reglas que caracterizan una práctica discursiva», reglas que "no se imponen desde el exterior», sino son parte constitutiva de lo "que ligan", Michel Foucault, La arqueología del saber, México, siglo xx। (10. a edición), 1984, p. 217), el de la construcción de la hegemonía en el campo de la cultura de lo que será la revolución mexicana en una línea que va de Carranza a Cárdenas pasando por Obregón y Calles, pero cuya génesis como nos lo sugiere Díaz Arciniega, la encontramos en la década de los veinte, aunque sus formas de operación institucional se verán favorecidas por la inyección que representó el exilio republicano español al doblar la década de los treinta.

Sobre el trasfondo de una Revolución acabada, constituida como el referente imaginario indiscutible, dado por hecho, sobreentendido básico que sirve a unos y otros, izquierdas y derechas, académicos y no académicos, para discutir en torno al pasado, tendrá lugar el desarrollo de la historiografía mexicana y, tal vez, como una de los factores explicativos del porqué de la primacía de lo empírico sobre lo teórico. Si la Revolución como discurso habia sido completado, era redondo, había conseguido ligar la dispersión de temporalidades y verse como punto culminante de toda historia pasada y futura; de esa misma manera, entonces, siguiendo a Foucault, podía instaurarse como una especie de a priori, visto no como condición de validez de un tipo de juicios, sino como «condición de realidad" para un tipo de enunciados históricos (Ibíd, 215-6). Entonces la tarea principal de los historiadores consistiria en enriquecer el discurso, adornarlo, ampliarlo con nuevas "positividades", es decir, aportar nuevas y mayores informaciones a un discurso histórico previamente constituido. A la historiografía profesional le correspondía entonces la función de retocarlo e incluso reencauzarlo cuando se viera necesario. De ahí que enfatice en mi acercamiento los aspectos ideográficos sobre el de los contenidos.

Intentaré dejar ver cómo esos procedimientos teóricos o programáticos se fueron constituyendo históricamente, y cómo la remodernización reciente permite o crea condiciones para su modificación, esto desde luego como correlato del debilitamiento de la hegemonía prí́sta en el campo de la ideología. 
La primera pregunta es si con la Revolución mexicana aparece o no un nuevo tipo de historiografía. Por Revolución entiendo el régimen político que surge de la guerra civil librada en la segunda década de este siglo, y cuya formalización en un régimen político estable - marcado por la hegemonía de un partido único- afectará los modos que conformaron a la institución historiográfica mexicana de este siglo.

En la historia moderna, "revolucionaria» por la naturaleza y alcance de sus medios técnicos de producción, la escritura de la historia en su forma secularizada parece ser un componente esencial. El proyecto de futuro abierto se acompaña con la necesidad de su cimentación en el campo del imaginario a partir del pasado. Es desde las urgencias del presente escindido que toda revolución en trance de ser reinscribe el pasado en la memoria de los individuos a partir de un punto cero (un nuevo calendario, nuevo santoral, renombramiento de los espacios urbanos, reubicación o destrucción de la estatuaria), intentando con ello inducir la aceptación de lo nuevo, todo lo cual pasa por la escritura, por las calles que se transitan o la escuela que se visita (proceso pedagógico). En este proceso de refiguración del pasado propiciado por la Revolución, la tarea de los historiadores fue fundamental, bien para reforzarla o bien para mostrar sus desvíos u olvidos. Esta «invención» (en su doble acepción de "encuentro" y "creación») de los orígenes tiene la virtud de dotar de densidad temporal a un presente que ha quedado suspendido debido al corte voluntario con la tradición. Sobre este imaginario (tipo de «ficción» en su doble acepción de "hechura" y "simulación") hace emerger lo nuevo. Es el momento cuando vemos nacer la historia y sus prácticas que se conocen y practican hoy en día en México.

Una de las cuestiones que la Revolución va a realizar en el campo de la cultura es intentar zanjar la disputa de la nación en torno a los "orígenes" sí «hispánicos" o «indígenas", la cual fue librada a lo largo del siglo XIX a partir de la independencia entre los bandos liberal y conservador. Sin embargo, la Revolución no inventará a la historia, pues ya desde el momento de la ruptura de lo que será México (la Nueva España) con la Corona, la "nueva nación» se ve en la necesidad de construir un pasado que la singularice y la identifique como única e irrepetible. Por eso, una de las reacciones (la liberal) será la de tratar de borrar o ridiculizar el pasado colonial; o la contraria, la de tratar de mediar con el pasado colonial buscando darle continuidad en el presente. Obviamente en ese momento la historia es eminentemente política: se trata de darse alrededor de un espacio (un territorio, una geografía desigual) un nombre «original» y unitario. 
A lo largo del XIX vemos asi surgir paulatinamente -más claramente a partir de las reformas liberales de la segunda mitad del siglo- una nueva simbología histórica, que condense los signos de identidad y los valores de la nueva patria. En este proceso, encontramos a los defensores del hispanismo que implica políticamente la restauración de la monarquía, y los seguidores del modelo republicano al modo francés y norteamericano, fervientes defensores de la idea de progreso. Benito Juárez vencedor en las guerras de Reforma y de la Intervención francesa (Maximiliano) sintetiza en el plano físico como simbólico lo que la nueva nación aspira a ser: una nación mestiza que no se avergüence de sus orígenes prehispánicos, y que a la vez se muestre capaz de abrirse irrestrictamente a los procesos de modernización resumidos en la aparición y desarrollo del ferrocarril. El colofón de este proceso se llama Porfirio Díaz, el Bismark mexicano, que concentrará el poder durante más de 30 años, y que no obstante su origen mestizo, intentará «blanquearse" para ponerse en concordancia con los valores raciales pregonados por la filosofía positivista del progreso, dominante en ese último cuarto de siglo.

Durante la tercera y cuarta década del período revolucionario, época de reformas sociales y disolución de la Hacienda porfiriana, resurge el problema del pasado antagónico debatido entre el pasado colonial de raíces hispánicas y el pasado del pueblo de raíces indígenas (ambos finalmente polisémicos, pero al ser leídos como si hubieran acontecido ayer, predomina el anacronismo: la figura de Cuauhtemoc como la de Bernal aparecen como héroes de la libertad y de la lucha contra el poder absoluto de la monarquía, percibidos como precursores de la emancipación de la nueva patria). Por otro lado, el siglo XIX se caracterizó por la escritura de historias generales y por el coleccionismo y resguardo de las antigüedades indígenas e hispánicas. Es la primera fase de la «museologización» de la historia. De hecho se crea el Museo Nacional de Historia hacia 1860 y las ruinas indígenas y los monumentos coloniales comienzan a ser exhibidas como símbolo del origen milenario de la nación en las exposiciones universales de fines de siglo (Cfr. Luis Gerardo Morales, Origenes de la museología mexicana. Fuentes para el estudio histórico del Museo Nacional, 1780-1940, México, Universidad Iberoamericana, 1994).

Lo que se conoce como institucionalización de la revolución que corresponde al creciente desplazamiento del mundo rural frente al urbano-industrial, más la creación de un foro político único para dirimir las contiendas entre los diversos jefes de la revolución y caciques regionales (fundación del Partido Nacional Revolucionario, fin de la conflictiva IglesiaEstado que marca el siglo del liberalismo) ve también el surgimiento de diversas instituciones dedicadas ex profeso a la investigación histórica: la 
fundación de la Casa de España en 1939, base de lo que será el Colegio de México, y el Instituto Mexicano de Geografía e Historia fundado en la década de 1930. Antes en 1919 ya había sido oficializada la Academia Mexicana de la Historia, filial de la de Madrid.

Ciertamente antes de estas fechas se escribe ya "historia». Están los cronistas civiles y religiosos, o los Clavijeros de la conciencia "criolla" (Carlos de Sigüenza y Góngora en el siglo XVII: Los antiguos príncipes mexicanos, ejemplos de virtudes políticas para los gobernadores virreinales, que ejemplifica el proceso de homologación de los propio con lo ajeno, y enseña lo cerca que está el pasado del presente), o los grandes coleccionistas y recuperadores de antigüedades como Orozco y Berra e Izcalbalceta mas tarde. Pero se trata de monjes, soldados, abogados, economistas, políticos, ingenieros o periodistas. Para estos la historiografía se convierte en una manera de prolongar algún tipo de alegato político o partidario, para beneficio propio, familiar o sustentante de un proyecto de sociedad, fincada por tanto en algún tipo de pasado. Están los "optimistas" de cara a un futuro mejor que el pasado como parte de una evolución mayor (un Riva Palacio, un Justo Sierra, Andrés Molina Enriquez,...) y los pesimistas o colgados del peso del pasado y de su necesaria recuperación (Alamán, Bustamante, entre otros....).

En este contexto ¿cómo se presenta el tránsito, mediado por la Revolución, entre la vieja historia pragmático-positivista y una nueva historia profesionalizante que busca alejarse de "la política» y marcar la distancia entre pasado y presente?

\section{CONSTITUCIÓN DE LA HISTORIOGRAFIA ACADÉMICA EN MÉXICO Y SUS INFLUENCIAS EN EL SIGLO XX}

Pivotes de la transformación de la historia en una disciplina "científica», cuya ambivalencia con todo no desaparecerá del todo hasta el día de hoy, son dos generaciones, una de adentro y otra de afuera.

\section{La generación de "adentro"}

Como en otros muchos campos, la generación reunida en torno a lo que se conoce como el Ateneo de la Juventud formado en 1906, va a jugar un papel muy importante en la constitución de la disciplina de la historia. Ellos son la generación de maestros de los nuevos historiadores que van a marcar los rumbos de su actividad. Son una especie de caudillos 
intelectuales (Krauze) que influirán el curso de las humanidades y otras disciplinas. Algunos nombres son Alfonso Reyes, Antonio Caso, José Vasconcelos, Pedro Henríquez Ureña, a los que se sumarán en la década de los veinte autores como Alfonso Teja Zabre o José Joaquín Izquierdo.

Tienen en común la crítica al positivismo dominante en el porfiriato y su crítica prefigura de algún modo a la Revolución en el campo de la cultura, en cuanto que pregonarán un regreso al humanismo contrapuesto al naturalismo cientificista. Sus autores predilectos están más allá de Comte y apuntan en dirección más bien de Bergson, Nietzsche, Poincaré. Son sensibles a la conmoción que significó el cambio de siglo, o tendencias modernistas previas a la Primera Guerra, y a las revoluciones como la rusa. Están preocupados por una historia más imaginativa en tránsito o tensión entre la ciencia natural y el arte o las ciencias del espíritu, entre la filosofía de la historia y la historia como una "ciencia sui generis» según definición del mismo Alfonso Reyes.

\section{La generación de "afuera"}

Está vinculada directamente al exilio español de los republicanos, con personalidades que dejarán honda huella en los centros académicos. Menciono sólo a algunos de ellos: Rafael Altamira, José Gaos, José Medina Echavarría, Ramón Iglesia, Wenceslao Roces, a los que se sumarán otros más jóvenes como Juan Ortega y Medina y Adolfo Sánchez Vázquez.

Dentro de su orientación humanista, tienen en común una gran apertura a la cuestión que plantea a las sociedades los desarrollos tecnológicos del Occidente moderno. Hay una pregunta también central sobre la contribución propia de Hispanoamerica a Occidente. Hay asimismo un programa metodológico de formación de historiadores en dirección de una historia restringida, controlable y relativa, sobre la base orteguiana, y fundamentada en El ser y tiempo de Heidegger, de una historiografía siempre en marcha, sin un punto último de llegada.

\section{Los mediadores de las influencias}

Son varios aunque hay algunos que se convertirán en los puntales sobre los que se constituyó la historiografía mexicana vigente, así como algunas instituciones entre las que destacan El Colegio de México y la UNAM. Entre las figuras de la historiografía, referentes básicos de las escuelas $y$ tendencias destacan los siguientes: 
Silvio Zavala, recién retornado de Madrid en la década de los treinta, en conexión con Altamira, para impulsar una historia sobria, pulcra, "no inventada" que limpie lo dicho hasta entonces de mentiras o de enunciados productos más de la imaginación que de la investigación. Promueve una historia como conocimiento "positivo" del pasado. Combina sus actividades de investigación cumpliendo también con tareas de funcionario.

Daniel Cosío Villegas, caracterizado como empresario cultural, es sin duda otro de los eslabones entre las dos influencias. Llega al campo de la historia con preguntas más propias de la ciencia social buscando con ello esclarecer el presente. Es uno de los grandes creadores de instituciones y tiene tiempo para formar equipos de investigadores para fabricar historias al estilo de la de Riva Palacio en el siglo xIx. En este sentido Cosío Villegas es un hombre situado en la cresta del entresiglo: su obsesión es el cómo de la historia nacional para detectar sus grandes momentos y sus desviaciones de la línea del progreso nacional ascendente. Una historia cuya principal responsabilidad radica en los hombres del poder. Será uno de los más influyentes en la siguiente generación de historiadores entre los que ya no será fácil distinguír al historiador-historiador del historiador periodista, sociólogo o economista. En este sentido será uno de los que privilegiará el modelo americano de ciencia social. Si la historia no es útil para el presente entonces no sirve. Encajona a la historia en la ciencia social en contraposión a las humanidades, la literatura y el arte. (De hecho esta batalla se librará en la década de los cincuenta en el COLMEX saliendo triunfador Cosío frente a Reyes, cuando el primero asuma la jefatura del Colmex en 1959).

Edmundo O'Gorman posee otras caracteristicas que lo mantienen distante tanto de Zavala como de Cosío, así como del poder. Su obsesión es también la historia nacional y una búsqueda irrestricta e incondicional de la verdad histórica, hecha sin concesiones. De ahí lo incómodo que pudo haber sido por los ámbitos por donde pasó, así como el halo de llanero solitario que lo acompañó. Sin embargo la influencia mayor que lo distingue es haber hecho la lectura de Ser y Tiempo al lado de José Gaos. Mostrar la imposibilidad ontológica de la verdad en la historia en la modernidad le ganó menos adversarios que admiradores, en especial, a la luz de los acontecimientos más recientes. A diferencia de otros, rara vez ocupó funciones públicas y planteó mejor que ninguno la posibilidad del intelectual crítico independiente en un pais, el de la revolución, que se construyó con la ayuda y colaboración estrecha de «los intelectuales".

En mi selección, sin duda sólo un punto de vista, son los tres historiadores más influyentes de la historiografía mexicana en el siglo xx, que 
emergieron de la conjunción de las dos influencias mencionadas arriba. Pero de los tres, a mi me parece que el más "moderno" es O'Gorman. Esta cuestión la retomo dspués de presentar algunas conclusiones breves.

1. La historiografía mexicana del siglo xx y su evolución no se explican sin considerar a estas dos generaciones hermanadas en México a fines de la década de los treinta, y salidas de dos revoluciones, una triunfante y otra derrotada. Dos generaciones que estructuran un proyecto de historiografía liberal (de cátedra), positivista (lo central es el trabajo y crítica de fuentes), y relativista (las partes es una función predominante sobre el todo).

2. Sin embargo, el trazo unitario fundamental, señala una pequeña variación, la que se ha querido ver como si se tratara de dos tendencias: la positivista y la historicista, la objetivista y la interpretativa, la histórica y la historiográfica o reflexiva.

A mí me parece que si se observa bien sólo existe una característica diferenciadora que tiene que ver con el papel que juega la subjetividad en el trabajo del historiador o expresado en la contraposición sujeto-objeto del esquema cognoscitivo.

Se puede plantear de la siguiente manera: en la línea del positivismo se seguiría el postulado de que a menor sujeto, se incrementa necesariamente la objetividad; en cambio en la línea historicista se afirmaría que entre mayor sea la fuerza argumentativa de la subjetividad, se tendrá mejor historia. Las consecuencias de estos postulados se reflejan en la arqueología de los textos históricos: en la primera el sujeto es el ausente, en cambio en el segundo, simplemente no hay historia (historiografía) sin sujeto.

Para el positivismo, la historia y su quehacer se presenta como no problemático: los conocimientos nuevos "objetivos" que aporta permiten tener una visión más "completa" del cuadro de la sociedad se den como se den las relaciones entre las partes. La ampliación del conocimiento sólo sirve para hacer más claro lo grande y complejo que es y ha sido la nación. Esta línea de trabajo que toma cuerpo durante la Revolución se eslabona claramente con aquella esbozada en el siglo XIX.

3. En la caracterización de esta "nueva historia» se está de acuerdo en los siguientes puntos:

- En fijar las fechas del nacimiento de esta historiografía revolucionaria, autodenominada como «científica». En la década de los treinta se sientan las bases de dos corrientes historiográficas en apariencia en pugna, una más "filosófica» y otra más "empirista", la propia de los 
historiadores. No deja de ser sintomático que las diferencias representadas por Edmundo O'Gorman y Silvio Zavala en los cuarenta, se prolonguen hasta recientemente cuando se reaviven a propósito de la conmemoración de los cinco siglos de 1492, la cual tuvo como secuela la renuncia de O'Gorman como presidente de la Academia Mexicana de Historia. Más allá de las diferencias formales, está a mi parecer la cuestión de las relaciones de los intelectuales con el Estado, en este caso de los guardianes del pasado.

- En señalar que en el campo de esta disputa "metodológica" (enmarcada ahora por el ámbito académico), el marxismo no logró constituirse en alternativa (La guerra fría se lo impidió entre otras razones igual que en otros muchos lugares). Pasa inadvertido en el seno de las instituciones académicas, y en todo caso su introducción y desarrollo se vincula más al campo de las ciencias sociales, aunque se tendrán al mismo tiempo traducciones como las de El Capital, obra de Wenceslao Roces.

- “Depolitizado» (o subsumido en el a priori histórico "revolucionario") el propósito explícito del quehacer histórico fue el de evitar la invención del pasado, para buscar su reproducción de acuerdo al proyecto de verdad histórica rankeano. Esta situación refuerza la conciliación de las partes enfrentadas en el siglo anterior. Esta situación se presenta más claramente a partir de la década de los cuarenta, postreforma agraria cardenista, y al abrigo de la política del régimen de la Revolución definido abiertamente como de "unidad nacional»; y al amparo de instituciones que facilitan que algunos estudiantes e investigadores puedan vivir de salarios y de becas destinados al estudio del pasado, en particular, al de la búsqueda de los orí. genes del ser nacional (se privilegian los momentos-nudo de la historia nacional) y a la explicación de los problemas que aquejan a la nación.

Los estudios históricos colindan, sin mezclarse del todo, con los de la antropología, etnología y de la arqueología, y la mayor preocupación se concentra en el pasado prehispánico y colonial. En el fondo, lo que se hace no es sino partir de la revisión de la "leyenda nacional" fabricada en la fase final del Porfiriato (para hacerla más sólida) por obras como México a Través de los Siglos(1884) de Vicente Riva Palacio y México y su Evolución Política (1902) de Justo Sierra. Sólo que ahora la revisión de la leyenda nacional estaría reforzada por autoridades «imparciales» al ser realizada desde instituciones dedicadas por oficio a la enseñanza e investigación histórica.

- La historia funciona como una gran fábrica productora de monografías en serie al estilo de los talleres fabriles del XIX (el taller de Daniel Cosío Villegas que produjo la Historia Moderna de México es un caso 
ejemplar, después vendría la Historia de la Revolución). El resultado es impresionante en cuanto al número de trabajos publicados y archivos recuperados en estos treinta años: tantos o más que lo que habían sido producidos hasta entonces, contando por supuesto con todo el siglo anterior.

Cien años después de la Independencia y con la distancia en el tiempo el pais contaba ya en estos años con una pasado ricamente diferenciado en cuanto a los periodos: prehispánicos, colonial o virreinal, nacional y contemporáneo (una buena expresión de esta fueron los volúmenes de la síntesis del historiador jesuita José Bravo Ugarte), para los que se contaba con figuras sobresalientes y discípulos en formación. A grandes rasgos dominan algunos temas como el de la conciencia criolla, basamento del nacionalismo mexicano, la tesis del mestizaje o fusión de las culturas y enfoques en el que todavía predomina el político, y en menor escala se vislumbra ya la historia social y demográfica y cultural de los años siguientes.

- La invención o creación de la figura del historiador profesional que predomina hasta hoy en día aparece y se desarrolla entonces con las siguientes características:

Ha de aprender a disciplinar su imaginación. (Frente a este postulado habrá un detractor permanente ilustre: Edmundo O"Gorman).

Es aconsejable una cierta asepsia política y social.

Ha de estar dispuesto de inicio al trabajo monográfico, a abandonar las generalidades y todo asomo de especulación, por tanto, ha de ser lo más reservado frente a la interpretación. El lugar de ésta en el texto, si acaso, será el de la introducción o el de las conclusiones.

Correlato del postulado anterior será el de evitar intentar establecer leyes históricas como en el viejo positivismo, por lo tanto ha de alejarse de cualquier tentación de profecía o predicción, para sujetarse a realizar aseveraciones sólo verdaderas y generalizaciones siempre de alcance limitado.

V

Este tipo de historiador implicó, a diferencia de la figura del historiador decimonónico, el distanciamiento del mundo de la política y de la empresa, así como del de los lectores, del anticuario o del historiador local, así como del «mundo social» en general, aspectos que serán reivindicados en la siguiente etapa (la de los sesenta), bien por miembros de la primera generación de historiadores como Luis González (defensor y promotor de la 
Microhistoria), o de la segunda generación con escritores al estilo de Héctor Aguilar Camín o Enrique Krauze.

Acorde con la tendencia general de la época, la aparición de la especialidad "historiografía» en el siglo xx en México, fue también un síntoma del abandono de toda filosofía de la historia en función de la investigación histórica pura, lo que colaboró a profundizar la fragmentación de los saberes y el recelo con las otras disciplinas: derecho, filosofía, sociología, economia y, finalmente, abrió la problemática teórica a la cuestión de lo empírico en la historia. Podemos recordar que en México al igual que en otros lugares, se aspira (hacia los treinta) a hacer una historia total no filosófica, sino empírica, para tener al final del proyecto un cuadro general de las civilizaciones; incluso son proyectos financiados por organismos internacionales para inscribir lo propio dentro de un conjunto mayor que podría verse como el de la constitución de las civilizaciones iberoamericanas (en este la labor de Rafael Altamira fue fundamental). Este proyecto es abandonado sin la necesaria autocrítica hacia los años cincuenta, al caer en la cuenta de la ingente tarea "empírica" que presupone, y de su imposibilidad material por falta de documentación. En su lugar, de manera intuitiva, se regresa al trabajo monográfico dominante aún hoy en la historiografía mexicana. Aquí se advierte en México un abandono de la reflexión teórica y el triunfo, por así decirlo, de la influencia empiricista norteamericana.

Creo que estos serían algunos de los rasgos principales de esta segunda etapa fundante de lo que sería «la nueva historiografía revolucionaria" que atraviesa tanto al antiguo como al nuevo régimen. Es una historiografía que se preocupa por el trabajo de recopilación de fuentes para ilustrar "científicamente" el proceso "verdadero" de la nación mexicana cuya culminación es el presente revolucionario (aunque ya desde los cuarenta se dibujan las corrientes revisionistas que dominarán las siguiente fase), pero también el momento en el que que se plantean preguntas de más alcance sobre el origen y el ser del mexicano en el tiempo. Sin duda es un periodo de gran actividad intelectual, no exclusivo de la historia, sino del arte y la cultura en México en general.

Este modelo de historia que engloba al menos a dos generaciones sufrirá el impacto del movimiento estudiantil y la crisis cultural de los sesenta. Llega entonces a la historia una nueva generación con mayor escolaridad, "más urbana» que le planteará preguntas al pasado sobre el por qué de la democracia ausente en un país como México. Más que antes y que todo, la historia regresa a ser la historia del presente. Se anuncia con ello una especie de "repolitización» de la historia que tensionará a las 
instituciones académicas, muchas de las cuales no rebasan los treinta años de vida.

VI

El 68 implicó una reorganización de la historiografía en varios sentidos:

1. El regreso de la historia a la política en este periodo sigue varios modelos, pero hay dos que sobresalen: Daniel Cosío Villegas y Pablo González Casanova. Por otro lado están escritores mexicanos como Octavio Paz o historiadores como Enrique Florescano que alrededor de revistas buscan reactivar la crítica de la historia y de la historiografía en México, revistas como Vuelta y Nexos que son expresiones del interés por abrir el discurso histórico al debate público. Este retorno de la política supone también la búsqueda del lector no académico o el regreso a la narrativa, inspirado en el género periodístico o en el género del cuento o novela mexicana (tipo Rulfo)

2. Supone también el encuentro de la historia con las ciencias sociales, ya que de lo que se trata no sólo es de interpretar el mundo, sino de su transformación. Mucha de la historiografía de estos años está marcada por el impulso de descubrir científicamente a los sujetos o actores que han transformado la historia y sus razones. Esto supone el peso enorme que tendrá el marxismo althusseriano, sobre todo para la historia social y la reinterpretación de la historia nacional. La historia se abre todavia más al influjo de las ciencias sociales, sobre todo cuando se trata de la economía o de la sociología y menos de la antropología o la psicología.

3. Finalmente, la Revolución mexicana se convierte en un campo central de estudio y aparece la historia contemporánea como un subespecialidad histórica. La Revolución alimentará el revisionismo historiográfico en detrimento del interés por los estudios coloniales porque ahora la pregunta por el origen de los que somos está más cerca, es más reciente: es propio del régimen de la Revolución frente al cual los historiadores son juez y parte. Por eso tal vez eso explique que las principales contribuciones a su esclarecimiento vengan de historiadores mexicanistas extranjeros o provenientes de otras disciplinas contiguas como la sociología o la ciencia política. Si la transformación política esperada no arriba, esto provoca que la mirada se vuelque sobre el de las resistencias al cambio así como se inicia el desarrollo de los estudios regionales y la historia oral.

A la generación anterior les obsesionó la pregunta por los orígenes de la mexicanidad; a la nueva generación, en cambio, les obsesionará la 
pregunta por el México de la crisis, el México después del milagro, y sobre todo su futuro. Quiere decir que el tema de la identidad nacional ha dejado de interesar y es sustituido por el interés de una historia política que dilucide el problema de las resistencias al cambio político y democrático, así como se da fuerza a los estudios y a las historias regionales. Estos se multiplicarán hacia la década de los setenta.

Al tiempo que busca encontrar la respuesta en la investigación del pasado, intenta también diseccionar el fantasma del autoritarismo moderno en sociedades que se dicen formalmente democráticas.

\section{EL MOMENTO ACTUAL: O"GORMAN, HISTORIADOR DE LA MODERNIDAD}

Hasta aquí he señalado básicamente dos etapas en el desarrollo de la historiografia en México: la primera que retoma la estafeta llegada del final del antiguo régimen, y consigue darle forma profesional, la continúa y lleva hasta los sesenta (1884-1965). La segunda que se sitúa de frente a la nación para pedirle cuentas, explicaciones de por qué se desvió, o por qué no dio lo que tenía que haber dado.

En la primera, la Revolución funciona como un implícito o condición de la fabricación del discurso nacional, en la lógica evolutiva dibujada ya por Justo Sierra en 1902: la Revolución es la culminación de un proceso de varios siglos.

En la segunda, en cambio, se enfrenta y se cuestiona esta evolución. La idea de la historia como progreso se viene abajo. Se atisba el fin de un ciclo histório y de la idea de lo nacional construida básicamente durante el siglo anterior al calor del debate político y de las celebraciones y rituales cívico educativo, confirmada "científicamente" por la historiografía de la Revolución y la apertura a otra historia, para otro momento: el actual.

En 1960 el presidente de la República Adolfo López Mateos encargó a un conjunto de ilustres intelectuales y artistas que realizaran un balance de su especialidad para conmemorar los 50 años de Revolución. A Edmundo O'Gorman se le encomendó la tarea relativa a la historia. Con ese motivo escribió un breve texto sobre la evolución de la historiografía en México. Nos recuerda ahí que no hay conciencia nacional sin conciencia del pasado, y su investigación es obra de los historiadores y su trasmisión de los pedagogos. Sin ellos no hay idea de pertenencia a una nación. Son los que proporcionan los elementos para su definición como entidad histórica. $Y$ esto tiene lugar en el reino del lenguaje y de la comunicación social. Su 
diagnóstico final es que la historia escrita hasta 1960 está dominado por el esencialismo: México es una entidad que desde siempre ha estado ahí a la que le ocurren cosas. En ese sentido la obra de Riva Palacio no ha sido rebasada (en alusión al proyecto de Cosío Villegas). Es decir, falta ver a México como un pais de oportunidades y posiblidades y no uno dominado por sus estereotipos o la fatalidad, un país con metas predestinadas. México y así su historia se tiene que ver no sólo como un legado, sino sobre todo como un quehacer corrresponsable. México y su historia como autoconstrucción y no sólo como parte de un proceso preconstituido.

O'Gorman concluye que la gran parte de la "nueva" historiogafía producida hasta esos años estaba inspirada por la del viejo régimen. La tesis fuerte sería: la revolución no había podido llegar cabalmente a los estudios históricos. En un texto poco antes de morir entregaría su legado con la misma observación ahora dirigida a los más jóvenes. (Edmundo O'Gorman, "La Historiografía», en México: Cincuenta Años de Revolución IV. La Cultura, México, 1960, pp. 193-203; Edmundo O'Gorman, Fantasmas de la narrativa historiográfica. Discurso leído en ocasión de la recepción del Doctorado Honoris Causa en Humanidades por la Universidad Iberoamericana, México, 1992.)

Actualmente se mantiene la situación general descrita por O'Gorman: a causa de una no autoapropiación de la disciplina, las grandes interpretaciones de la historia siguen siendo dominadas por mexicanistas extranjeros, mientras los nacionales siguen siendo grandes trabajadores de archivos y hacedores de monografías con poca interpretación. La inercia del positivismo sigue marcando buena parte de la formación de los historiadores.

Dos etapas, entonces, en el desarrollo de la historiografía en México: la primera que se abocó a la tarea de retomar la estafeta llegada del siglo XIX a fin de darle más solidez al discurso nacional fabricado y la segunda que se ubica de cara frente a la nación. En la primera la Revolución funciona como un implícito o condición de la fabricación del discurso nacional, y la segunda que enfrenta a la Revolución. Esto significa política e historiográficamente el fin de la revolución y de la idea de lo nacional construida en el siglo xix y reafirmada por la Revolución, y la apertura o búsqueda de una nueva historia para otro momento histórico. En poco tiempo, (la historia como disciplina es de reciente creación), la historiografía enfrenta el reto de revisar sus bases para edificar otras posibilidades. 